\title{
High eosinophil blood counts are associated with a shorter length of hospital stay in exacerbated COPD patients - a retrospective analysis
}

Timm Greulich ${ }^{1 *}$, Julia Tüffers ${ }^{1}$, Sina Mager ${ }^{2}$, Anna Eder ${ }^{1}$, Michael Maxheim', Peter Alter ${ }^{1}$, Bernd Schmeck ${ }^{1,3}$ and Claus F. Vogelmeier ${ }^{1}$

\begin{abstract}
Background: In COPD, the course of the disease including morbidity and mortality is strongly associated with severe exacerbations. The current GOLD recommendations emphasize blood eosinophil counts as a marker for responsiveness to inhaled corticosteroids (ICS). Retrospective analyses from randomized clinical trials indicate a favorable response to systemic corticosteroids in exacerbated COPD patients with blood eosinophils $>2 \%$, however data outside clinical trials are scarce.

Patients and methods: We retrospectively evaluated data from 1007 cases of patients who were admitted to the University Medical Center Marburg between 01/2013 and 12/2018. All patients had been diagnosed with an acute exacerbation of COPD (ICD-10 J44.0/J44.1). Our analysis was based on a subgroup of 417 patients in whom a full blood cell count was obtained at the day of admission. Patients were predominantly male (63.3\%), had a median age of 74 years (IQR 65 years - 83 years) and a median FEV1 of 1.03 I (42.6\% predicted). We compared the hospital length of stay and other outcome parameters using established thresholds for the eosinophil blood cell count (100 and 300 eosinophils/ $\mu$ land $2 \%$ ).

Results: Patients with low eosinophils $(<2 \%,<100$ cells/ul) had a longer median time in hospital (length of hospital stay - LOS) as compared to patients with high eosinophils (<2\%: 9.31 vs. $\geq 2 \%: 7$ days, and $<100 / \mu$ l: 10 vs. 100-300/

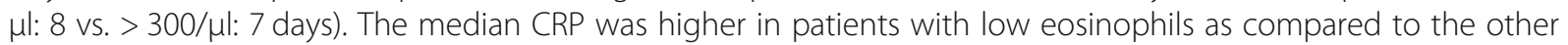
groups (<2\%: 22.7 vs. $\geq 2 \%: 9$ mg/dl and < 100: 25 vs. 100-300: 13.5 vs. > 300: $7.1 \mathrm{mg} / \mathrm{dl}$ ). Time to re-hospitalization or time to death did not differ between strata of eosinophils. Sensitivity analysis in a subgroup of patients in which pneumonia was excluded by chest $x$-ray did not significantly alter the results.

Conclusion: The results support the hypothesis that patients with severe COPD exacerbations and elevated blood eosinophil counts respond better to systemic corticosteroid treatment than patients with a non-eosinophilic exacerbation.
\end{abstract}

Keywords: COPD, Eosinophil, Infection and inflammation

\footnotetext{
* Correspondence: greulich@med.uni-marburg.de

'Department of Medicine, Pulmonary and Critical Care Medicine, University

Medical Centre Giessen and Marburg, Philipps-University, Centre for Lung Research (DZL), 35043 Marburg, Germany

Full list of author information is available at the end of the article
} 


\section{Background}

Morbidity and mortality of Chronic Obstructive Pulmonary Disease (COPD) is strongly associated with severe exacerbations [1].

The current GOLD recommendations emphasize blood eosinophils (eos) as a marker for responsiveness to inhaled corticosteroids (ICS) [2]. The recommended thresholds are $<100$ cells $/ \mu \mathrm{l}$ and $>300$ cells $/ \mu$ l. These recommendations are based on a high number of analyses from both, population based cohort studies and secondary analyses from randomized clinical trials: In a subgroup of COPD patients of the Copenhagen General Population Study, higher baseline blood eos were associated with an increased incidence for severe exacerbations [3]. Similar findings have also been recognized in a number of randomized controlled trials comparing treatment with LABA as compared to ICS/ LABA $[4,5]$. In a post-hoc-analysis of the WISDOM-study, Watz et al. found that higher blood eosinophils were associated with an increased exacerbation rate after steroid withdrawal in patients pre-treated with triple therapy [6]. Further evidence comes from pharmaceutical parallelgroups randomized clinical trials in which inhaled triple therapy has been compared to different dual combinations. Higher blood eosinophils were usually associated with higher ICS efficacy [7-9].

The therapeutic and prognostic implications of blood eosinophils during an exacerbation are less clear: In a post-hoc analysis Bafadhel et al. evaluated the rate of recovery of eosinophilic (blood eos $\geq 200$ cells/ $\mu$ l and/or $\geq$ $2 \%)$ and non-eosinophilic exacerbations from COPD subjects $(n=243)$ who participated in a multi-centre randomised control trial [10]. In the eosinophilic exacerbation population, the length of hospital stay was shorter than in patients with non-eosinophilic exacerbations following treatment with oral corticosteroids. The CRP tended to be normal [10].

Because data from real life settings confirming these RCT-based findings are scarce, we retrospectively evaluated the association between baseline eosinophil counts and clinical outcomes in patients hospitalized due to an exacerbation of their underlying COPD.

\section{Methods}

\section{Patient population}

In this analysis, we present retrospectively collected data from 1007 exacerbations which were treated at the University Medical Center Marburg between 01/2013 and 12/ 2018. All patients had been diagnosed with an acute exacerbation of COPD according to the ICD code (J44.0/J44.1). According to national guidelines valid at the time of data collection, there were no standardized criteria for hospital admission due to acute exacerbation. The decision was based on the patients' clinical impression, reflected by the metabolic status (assessed by blood gas analysis), breathing frequency and oxygen saturation.

Patients were predominantly male (65\%), had a median age of 72 years (IQR 64 years - 81 years) and a median $\mathrm{FEV}_{1}$ of $1.02 \mathrm{l}$ (39.3\% predicted). Our analysis was based on a subgroup of 417 cases of patients in whom a full blood cell count was obtained at the day of admission. These patients exhibited similar baseline characteristics (63,3\% male, 74 years of age, $\mathrm{FEV}_{1} 1.03$ l, 42.6\% predicted) (Table 1).

Chart reviews were done to describe further characteristics of these patients and to evaluate their clinical outcome. From the routine medical records we transferred and analyzed the following parameters: Case Mix Index (CMI) - a formula of the Diagnosis Related Groups (DRG) system for the calculation of patients' case severity, which is used as a controlling instrument of hospitals relevant for financial reimbursement - as a rough marker of disease severity, inflammatory markers, other basic laboratory values, and spirometry. As primary endpoint, we compared the length of hospital stay. Further analyses described other markers of disease severity and outcome (re-hospitalization and mortality within our hospital as well as the annual severe exacerbation rate within our hospital) according to the above mentioned eosinophil blood cell count strata (100 and 300 eosinophils/ $\mu$ l and $2 \%$ [2, 10-12]).

As this was a purely retrospective analysis from clinical routine data, we obtained a waiver by the ethics committee because a formal review was considered as not mandatory (EM_MR_greulich_130320).

\section{Subgroup analyses}

Two separated subgroup analyses were performed: Firstly, we analyzed a subgroup of 243 cases of patients, who - according to the medical records - did not receive systemic steroids before the full blood count was obtained. Baseline characteristics of these patients were similar to the primary analysis population and can be seen in supplementary Table S1.

Secondly: For the vast majority of cases admitted to our hospital, chest $\mathrm{x}$-rays were performed as part of clinical routine (>95\%). As exacerbations of COPD and pneumonia may overlap in some cases, we performed an additional analysis, excluding patients with radiological signs of pneumonia $(n=89)$, leaving a study population of 322 exacerbations. Baseline characteristics were similar and can be seen in supplementary Table S2.

\section{Statistical analyses}

As data were not normally distributed, Mann-Whitney tests and Kruskal-Wallis tests were applied to compare metric outcome variables between different eosinophil strata. The exact fisher test was applied to compare categorical variables. For patients that were re-hospitalized in our hospital or died in our hospital during the observational time 
Table 1 Baseline characteristics

\begin{tabular}{lllllll}
\hline & All & $<100[\mathrm{eos} / \mu \mathrm{l}]$ & $100-300[\mathrm{eos} / \mu \mathrm{l}]$ & $>300[\mathrm{eos} / \mu \mathrm{l}]$ & $<2[\%]$ & $\geq 2[\%]$ \\
\hline $\mathrm{N}$ & 417 & 219 & 129 & 69 & 276 & 141 \\
Age [years] & $74.0(65.0-83.0)$ & $73.0(63.0-83.0)$ & $73.0(65.0-81.0)$ & $76.0(67.0-83.0)$ & $72.0(64.0-82.0)$ & $76.0(67.0-83.0)$ \\
Male sex [\%] & 63.3 & 60.3 & 67.4 & 65.2 & 61.2 & 67.4 \\
Packyears & $40.0(30.0-59.0)$ & $40.0(22.0-50.0)$ & $40.0(30.0-50.0)$ & $45.0(30.0-60.0)$ & $40.0(25.0-50.0)$ & $40.0(30.0-60.0)$ \\
FEV1[1] & $1.03(0.74-1.44)$ & $0.98(0.71-1.30)$ & $1.06(0.74-1.50)$ & $1.10(0.81-1.54)$ & $1.00(0.71-1.33)$ & $1.11(0.78-1.50)$ \\
FEV1 [pred. \%] & $42.6(30.6-54.8)$ & $38.3(29.5-51.9)$ & $45.3(30.8-58.2)$ & $42.6(34.4-58.8)$ & $41.8(29.1-53.0)$ & $42.6(33.9-57.6)$ \\
FEV1/NC & $46.0(37.1-57.2)$ & $45.2(35.6-54.5)$ & $44.4(36.4-62.3)$ & $50.7(41.4-55.5)$ & $44.8(35.5-56.0)$ & $47.5(38.5-58.5)$ \\
\hline
\end{tabular}

Displays the baseline characteristics depending on the blood eosinophils on the day of admission. Continuous parameters are expressed as Median and (IQR). Mann-Whitney test was used for two groups comparisons, Kruskal-Wallis test with Dunn's test for three groups comparisons. No significant differences were detected between the groups.

period, Kaplan-Meier curves were used to visualize the results and Wilcoxon log rank test was applied to compare the data between the strata. IBM SPSS statistics version 24 (IBM, Armonk, New York, USA) was used for all calculation, graphs were constructed using IBM SPSS or GraphPad version 7 (GraphPad, San Diego, CA, USA).

\section{Results}

Of the 417 cases of patients that were included in the study, $276(66.2 \%)$ had a peripheral blood eosinophil count of $<2 \%$, whereas 141 cases (33.8\%) had $\geq 2 \%$ eosinophils of the total leucocyte count. In the absolute strata, there were 219 exacerbations $(52.5 \%)$ with eosinophil counts $<100$ cells/ $\mu \mathrm{l}, 129$ (30.9\%) with eosinophils between 100 and 300 cells/ $\mu \mathrm{l}$ and $69(16.5 \%)$ that exhibited absolute eosinophilic cell counts $>300 / \mu \mathrm{l}$.

\section{Length of hospital stay}

Patients with low eosinophils $(<2 \%,<100$ cells $/ \mu$ l) had a longer median time in hospital (length of hospital stay -
LOS) as compared to patients with high eosinophils (Fig. 1). This was true for both, relative and absolute values.

Restricting the analysis to patients naïve for systemic steroids (before blood collection) yielded similar outcomes: The median LOS in patients with low eosinophils was longer than in their respective control group $(<2 \%$ : 9 vs. $\geq 2 \%: 7$ days, $p<0.05$ ). The same applied to the absolute eosinophilic groups $(<100 / \mu \mathrm{l}: 9.18$ vs. $100-300 / \mu$ l: 7 days, n.s.; $100-300 / \mu \mathrm{l}$ : 7 vs. $>300 / \mu \mathrm{l}$ : 6.54 days, n.s.; $<100 / \mu \mathrm{l}$ : 9.18 vs. $>300 / \mu \mathrm{l}$ : 6.54 days, $p<0.05)$.

Additionally, restricting the analysis to patients without consolidation on chest $\mathrm{x}$-ray yielded similar results, too: The median LOS in patients with low eosinophils was longer than in patients with a higher relative number of blood eosinophils $(<2 \%$ : 9 vs. $\geq 2 \%$ : 7 days, $p<0.05)$. Similar trends could be observed regarding strata derived from absolute numbers of eosinophils $(<100 / \mu \mathrm{l}$ : 9.96 vs. $100-300 / \mu \mathrm{l}: 8$ n.s.; $100-300 / \mu \mathrm{l}$ : 8 vs. $>300 / \mu \mathrm{l}$ : 6.54 days, n.s.; $<100 / \mu \mathrm{l}$ : 9.96 vs. $>300 / \mu \mathrm{l}$ : 6.54 days, $p<0.01)$.
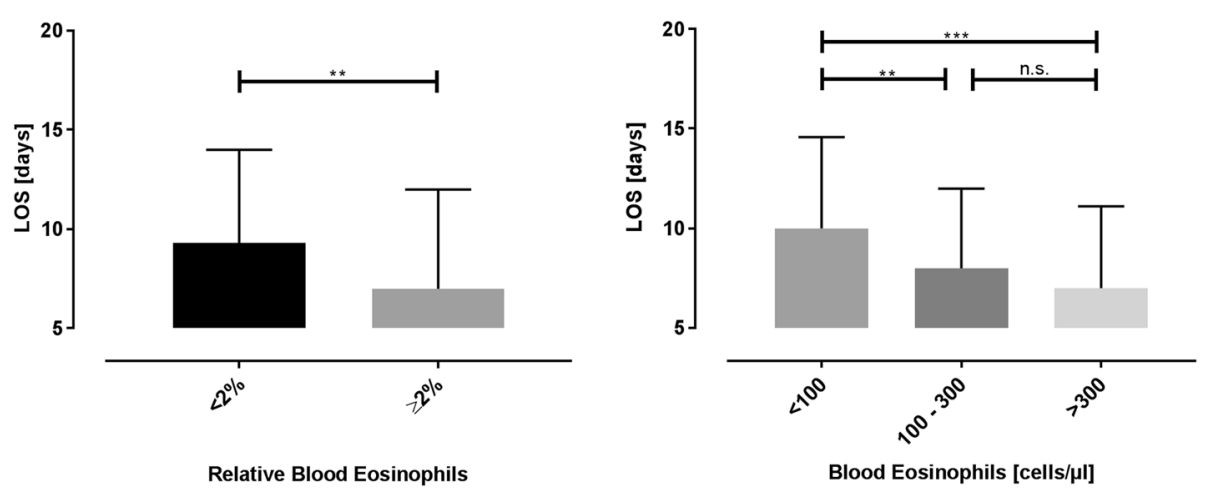

Fig. 1 Hospital length of stay according to the blood eosinophils at the day of admission. Displays the median (+ IQR) hospital length of stay according to the blood eosinophils at the day of admission. Patients with a low relative eosinophil count experienced a longer hospital stay as compared to patients with a high relative eosinophil count (left diagram; $p<0,005$; Mann-Whitney test). Patients with low absolute number of blood eosinophils also exhibited a longer length of hospital stay as compared to patients with an intermediate or high number of blood eos (right diagram; $p<0.005 ; p<0.001$; Kruskal-Wallis test with Dunn's test) 


\section{Inflammatory markers}

The median CRP was higher in patients with low eosinophils as compared to the other groups (Fig. 2). The same trend could be observed for a number of further inflammatory markers (Table 2).

Subgroup analyses regarding inflammatory markers (firstly, excluding cases of exacerbations in nonsystemic-steroid-naïve patients; secondly ruling out cases with signs of pneumonia in the chest $\mathrm{x}$-ray) confirmed our analyses in trends at similar significant levels (supplementary Table S3 and Table S4).

\section{Case mix index}

A significant difference could be established between the Case Mix Index in the different strata of eosinophil blood counts. The analysis showed that patients with a lower relative eosinophilic count recorded a higher median CMI than those with a relative eosinophilic count $\geq 2 \%$ (<2\%: 0,91 vs. $\geq 2 \%: 0,74, p<0,0001$ ). The same applied to the absolute eosinophilic counts and the particular thresholds (<100cells/ $\mu \mathrm{l}: 0,91$ vs. $100-300$ cells $/ \mu \mathrm{l}$ : 0,74 vs. $>300$ cells/ $\mu \mathrm{l}: 0,74, p<0,01)$.

\section{Longitudinal analyses}

Overall $72.66 \%$ of the 417 included exacerbated patients experienced a re-hospitalization to our hospital (median follow-up of 254 days) while $28.78 \%$ died during followup in our hospital (median follow-up of 1469 days). Time to hospital readmission (Fig. $3 \mathrm{a}$ and b) or time to death (in-hospital-mortality only, Fig. 3c and d) did not differ between the groups. Repeating the analysis in the above defined subgroups did not alter the results (data not shown).

Of all 417 cases of patients with a full cell blood count at the day of admission, we observed the annual severe exacerbation rate until the date of death or endpoint of this study (31.12.2018) according to the levels of blood eosinophil counts. In both relative and absolute strata, the differences in median exacerbation rate were not statistically significant ( $<2 \%$ : 0.27 vs. $\geq 2 \%$ : 0.25 annual exacerbations in the relative and $<100 / \mu \mathrm{l}$ : 0.27 vs. 100 300/ $\mu$ l: 0.26 vs. $>300 / \mu \mathrm{l}: 0.29$ in the absolute strata).

\section{Discussion}

In our retrospective analyses, patients suffering from a non-eosinophilic exacerbation $(<2 \%$ or $<100$ cells $/ \mu \mathrm{l})$ stayed in the hospital for a longer period of time as compared to patients exhibiting a higher eosinophil count at the day of admission. These patients tended to demonstrate a stronger general inflammatory reaction, based on their levels and numbers of CRP, leucocytes, neutrophile fraction, PCT, and fibrinogen. The nature of the exacerbation was not relevant with regard to rehospitalization (due to COPD) and/or death (in our hospital). Our real world data confirm and enhance existing data from clinical trials and other (mainly smaller) cohorts.

Comparing our study to published results from other studies, at least three important manuscripts have to be taken into account. Bafadhel et al. analyzed 243 COPD subjects at presentation to hospital with an exacerbation that participated in a multi-center randomized controlled trial in Great Britain evaluating early rehabilitation [10]. Duman et al. performed a retrospective chart review in a tertiary teaching hospital, recruiting 1704 patients hospitalized with COPD exacerbation [13] in a large hospital in Turkey. MacDonald et al. conducted two cohort studies $(n=242$ for the restrospectively collected derivation cohort, $n=99$ for the prospectively collected validation cohort) observing patients hospitalized for an acute exacerbation of COPD in Melbourne [14].
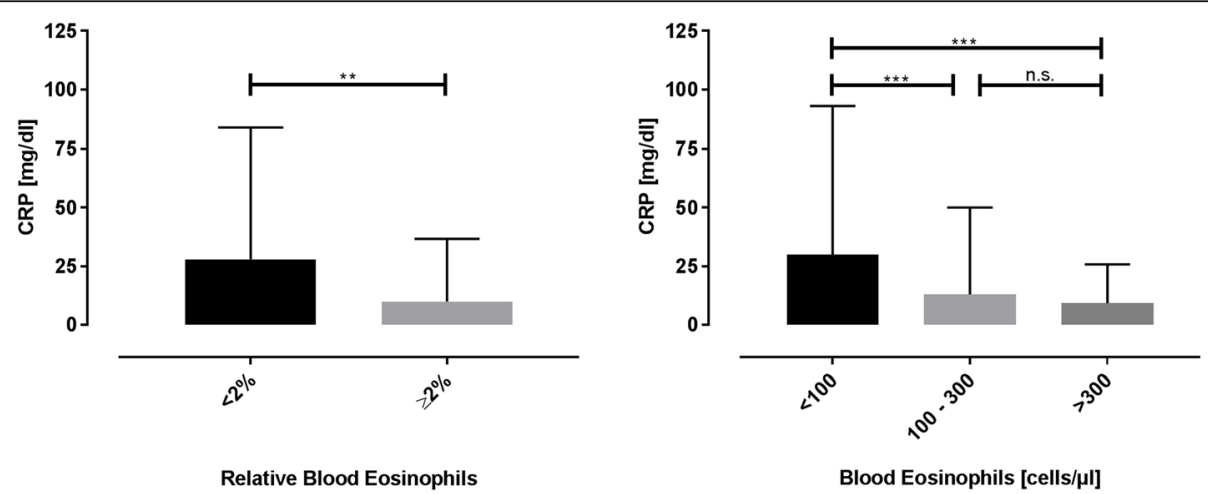

Fig. 2 C-reactive protein according to the blood eosinophils at the day of admission. Shows the median (+ IQR) C-reactive protein (CRP) according to the blood eosinophils at the day of admission. Patients with a low relative eosinophil count showed a higher CRP than patients with a high relative eosinophil count (left diagram; $p<0.001$; Mann-Whitney test). Patients with low absolute numbers of blood eosinophils also exhibited a higher CRP than patients with an intermediate or high number of blood eos (right diagram; $p<0.001 ; p<0.001$; Kruskal-Wallis test with Dunn's test) 
Table 2 Inflammatory markers

\begin{tabular}{|c|c|c|c|c|c|c|c|c|}
\hline & All & $<100 \mathrm{eos} / \mu \mathrm{l}$ & 100-300 eos/ $\mu \mathrm{l}$ & $>300 \mathrm{eos} / \mu \mathrm{l}$ & $\boldsymbol{P}$-value & $<2 \%$ & $\geq 2 \%$ & $\boldsymbol{P}$-value \\
\hline $\mathbf{N}$ & 417 & 219 & 129 & 69 & & 276 & 141 & \\
\hline Leucocytes [g/l] & $11,2(8,32-14,8)$ & $12,0(8,41-16,5)$ & $11,2(8,49-13,5)$ & $9,98(7,99-14,6)$ & n.s. & $12,5(9,06-16,1)$ & $9,38(7,67-12,2)$ & $\S \S \S$ \\
\hline Neutrophils [\%] & $78,0(68,0-88,0)$ & $85,0(76,0-91,0)$ & $73,0(65,0-81,0)$ & $65,0(56,0-76,5)$ & $\begin{array}{l}\text { H** }^{* *} \\
\# \# \# \\
\$ \$\end{array}$ & $83,5(76,0-90,0)$ & $67,0(57,5-76,0)$ & $\S \S \S$ \\
\hline Procalcitonin $[\mu \mathrm{g} / \mathrm{l}]$ & $0,05(0,05-0,20)$ & $0,10(0,05-0,33)$ & $0,05(0,05-0,20)$ & $0,05(0,05-0,05)$ & \#\# & $0,10(0,05-0,25)$ & $0,05(0,05-0,10)$ & $\S$ \\
\hline Fibrinogen [g/l] & $5,05(4,00-6,80)$ & $5,30(4,10-14,0)$ & $5,00(3,80-6,43)$ & $4,50(3,50-5,80)$ & \#\# & $5,14(4,00-14,0)$ & $4,70(3,65-6,08)$ & $\S$ \\
\hline CRP [mg/l] & $20,0(6,00-66,5)$ & $30,0(12,0-93,0)$ & $13,0(2,50-50,0)$ & $9,25(2,50-25,8)$ & $\begin{array}{l}\text { *** } \\
\# \# \#\end{array}$ & $28,0(10,0-83,9)$ & $10,0(2,50-36,6)$ & $\S \S \S$ \\
\hline
\end{tabular}

Median and IQR of inflammatory markers according to the blood eosinophils at the day of admission. In general, patients with a low relative eosinophil count showed a higher inflammatory markers as compared to patients with higher eosinophils (Mann-Whitney test for two groups comparisons, Kruskal-Wallis test with Dunn's test for three groups comparisons). $N=417$ for leukocytes and granulocytes, $n=156$ for Procalcitonin, $n=406$ for fibrinogen; ${ }^{*}$ significant between $<100$ and 100-300; \# significant between $<100$ and > 300; $\$$ significant between 100 and 300 and $>300$; $§$ significant between $<2 \%$ and $\geq 2 \%$

In all four studies, the percentage of eosinophilic exacerbations was roughly comparable. It was approximately $20 \%$ (threshold: $\geq 2 \%$ ) in the British and Turkish studies and $33,8 \%$ in our study. The same was true if absolute eosinophils were used to stratify the groups $(>300$ cells $/ \mu$ l defined as eosinophilic): We found $16,3 \%$ to be eosinophilic while the colleagues in Melbourne found $25,2 \%$. Taken together, one quarter to one third of exacerbations seem to be eosinophilic regardless of the setting or continent in which the studies have been performed.
Regarding outcome parameters, again we find our results in line with the other observations: Although assessed with different methods (comparison of means, comparison of median values, Kaplan-Meyer analysis) in every study, the length of hospital stay was significantly longer in patients with low eosinophils as compared to patients experiencing an eosinophilic exacerbation. Bafadhel et al. described different clusters of exacerbations, leading to different exacerbation phenotypes [15]. This finding provides a logical explanation for the differential responsiveness to ICS-treatment of COPD patients, dependent
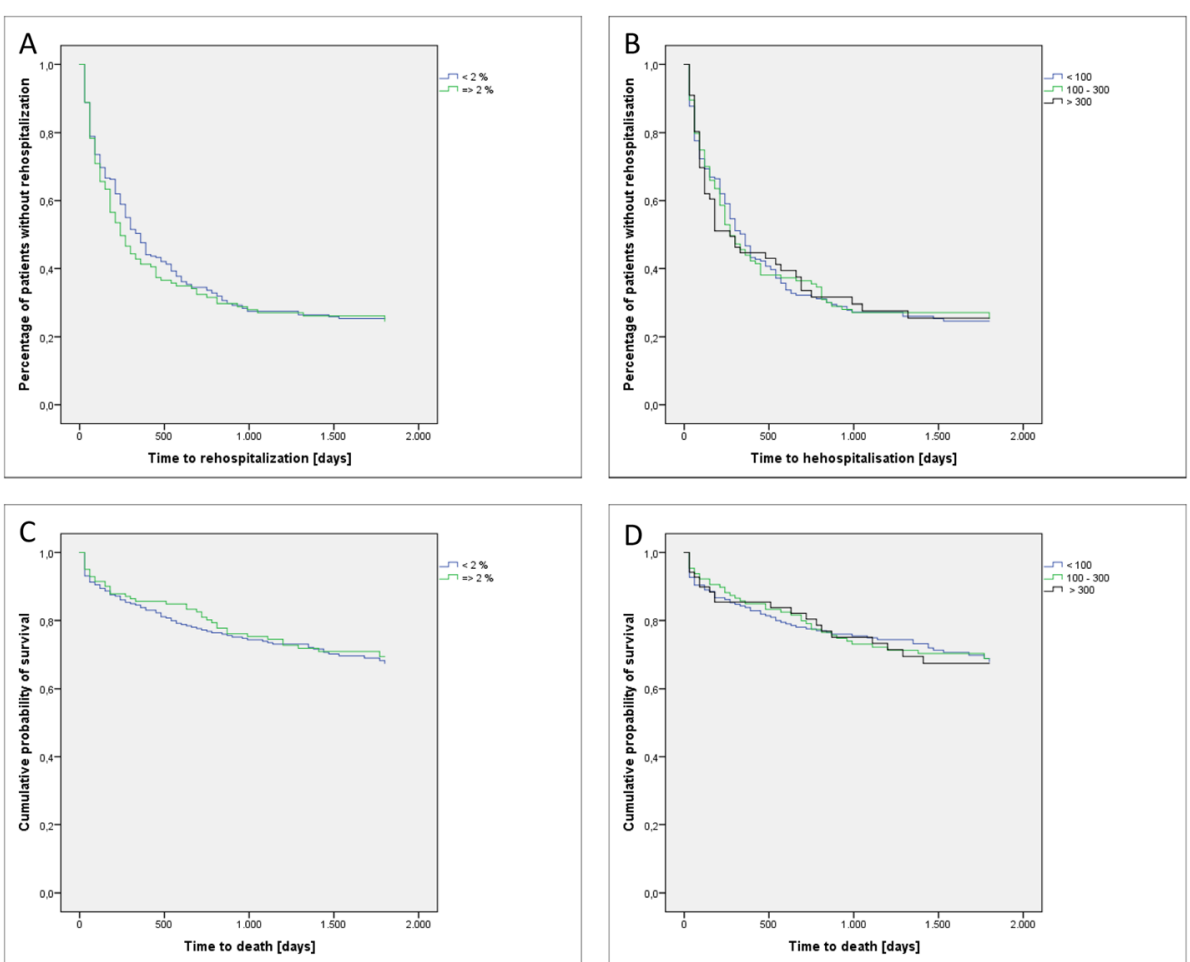

Fig. 3 Survival rates according to the blood eosinophils at the day of admission. Time to re-hospitalization (a) and $\mathbf{b})$ ) or death (c) and $\mathbf{d}$ )) according to the blood eosinophils at the day of admission. No significant differences were detected (Log-Rank Mantel-Cox) between the groups 
on the number blood eosinophils [4, 16, 17]. One may speculate that the association between acute severe exacerbations with eosinophilic inflammation and a shorter length of hospital stay may be due to a rapid response to steroid treatment. An alternative explanation would be that that differences in the type of ICS prescribed could be responsible for the differences in treatment response. However, analyzing the distribution of different ICS in the eosinophilic and non-eosinophilic strata, yielded no significant differences (supplementary Table S5).

Regarding parameters of inflammation we present similar results to the studies of Bafadhel, MacDonald and Duman $[10,13,14]$. We confirm their findings that lower eosinophils are associated with higher levels of inflammation. As the median procalcitonin was higher in this group, this might reflect more bacterial inflammation $[18,19]$. We enhance the number of parameters by demonstrating that this is not only true for CRP but also for PCT, leukocytes, neutrophils, and fibrinogen. Taken together with the longer hospital stay these findings again support the existence of different exacerbation phenotypes and the notion that a rather non-eosinophil phenotype (which may include bacterial or viral infections) may need a longer time to clinical improvement.

With regard to the sometimes challenging differential diagnosis between a bacterial exacerbation of COPD and a community-acquired pneumonia, we tried to account for that by repeating our analysis after having excluded patients with signs of consolidation on chest $x$-ray, which did not change our results. In our opinion, this further reinforces the generalizability of the results.

A high CMI was associated with low blood eosinophil counts, whereas the opposite applied to patients with high eosinophils. These findings go along with the previously discussed results (longer LOS and higher level of inflammation in patients with low eosinophil blood counts) and support our hypothesis of a more rapid response to corticosteroid treatment in patients with eosinophilic exacerbations. However, the possibility has to be taken into account that a high disease severity itself, reflected by a high CMI, might also be the reason for the strongly varying courses of disease in patients with acute exacerbations of COPD. Due to the retrospective nature of the study we do not see a way to further examine this matter.

With regard to long-term outcome, we did not find any correlation between exacerbation phenotype and rehospitalization or death. This is in line with the results of Bafadhel and Duma $[10,13]$ but contradicts what has been found by MacDonald and colleagues [14]. A number of explanations are possible: As our study is based on chart reviews only and no formal assessment of survival has been accomplished, we can only report re-hospitalization and/or death that occurred in our hospital. Furthermore, long term health outcomes in COPD may be more closely related to disease severity [20], number of exacerbations [21], or comorbidities [22, 23].

A relatively new finding of the current study is that lung function was worse in patients with a noneosinophilic exacerbation (significant only in subgroup analysis. In two prospective clinical studies, Crisafulli et al. analyzed clinical predictors of a) treatment failure within 7 days and b) prolonged hospital stay in patients with severe exacerbations of COPD. In the first study they found that treatment failure was associated with worse lung function, while in the second study there was no difference in lung function between patients with a hospital stay $\leq 7$ and $>7$ days $[24,25]$. Furthermore, in a recently published retrospective study, Tang et al. investigated the relationship of blood eosinophilia with pulmonary function parameters in 247 exacerbated COPD patients [26]. They also found that patients with high levels of blood eosinophil counts ( $\geq 2 \%$ eos) had better lung function than patients in the non-eosinophlic group $(<2 \%$ eos). This goes in line with a prospective observational study of Ko et al., who detected an improvement of FEV1 in 346 exacerbated COPD patients with eosinophil blood counts $\geq 2 \%$ after 12 months, when compared to the spirometry records at baseline [27]. Since we did not differentiate whether spirometry was performed in the beginning of admission or towards the end of the hospital stay (after treatment response), we cannot systematically assess whether lung function was a confounding factor or a treatment result. As our data are in line with other studies, we think both explanations may be possible.

There are a number of limitations to our study: Firstly, the retrospective study design limits the interpretation of our data. Secondly, no standardized discharge criteria have been used. Thirdly, we could not assess rehospitalization or mortality that occurred outside our hospital. Fourthly, although recommended by guidelines and hospital standard operating procedures, in some cases systemic steroids may not have been administered. However, repeating the analysis without cases in which systemic steroid treatment had not been documented did not change the results significantly (data not shown). Fifthly, we did not assess the exacerbation phenotype systematically. Albeit these limitations, the present study adds to the growing body of evidence that blood eosinophils may serve as a biomarker not only for ICSresponsiveness with regard to the prevention of exacerbations but also for responsiveness towards systemic steroids during an acute exacerbation of COPD. We enhance the generalizability of pre-existing data by introducing real-world data (as compared to RCT data [10]) from a high-standard Western European country (as compared to the other available studies $[13,14]$ ). 


\section{Conclusion}

In summary, our data support the hypothesis that patients with low eosinophil counts may be less responsive to systemic corticosteroids when compared to patients with high eosinophils. This may translate into a longer hospital length of stay.

\section{Supplementary information}

Supplementary information accompanies this paper at https://doi.org/10. 1186/s12931-020-01365-5.

Additional file 1: Table S1 displays the baseline characteristics according to the blood eosinophils of patients in whom systemic steroids were administered only after the blood samples had been taken. Continuous parameters are displayed as Median and (IQR). Chi-Square test was performed to compare gender between the groups. For continuous parameters: Mann-Whitney test was calculated for two groups comparisons, Kruskal-Wallis test with Dunn's test for three groups comparisons. ${ }^{*}$ significant between $<100$ and 100-300; \# significant between $<100$ and > 300; \$ significant between 100 and 300 and > 300; § significant between $<2 \%$ and $\geq 2 \%$. Table $\mathbf{S 2}$ displays the baseline characteristics of patients without any signs of pneumonia $(n=322)$. Continuous parameters are displayed as Median and (IQR). Chi-Square test was performed to compare gender between the groups ( $\&$ indicates a significantly different gender distribution). For continuous parameters: MannWhitney test was calculated for two groups comparisons, Kruskal-Wallis test with Dunn's test for three groups comparisons. ${ }^{*}$ significant between $<100$ and 100-300; \# significant between < 100 and > 300; \$ significant between 100 and 300 and $>300$; $\S$ significant between $<2 \%$ and $\geq 2 \%$. Table S3 displays inflammatory markers according to the blood eosinophils of patients in whom systemic steroids were administered only after the blood samples had been taken. Continuous parameters are displayed as Median and (IQR). $N=243$ for leukocytes, $n=238$ for neutrophils, $n=$ 86 for Procalcitonin, $n=234$ for fibrinogen. $n=239$ for CRP; * significant between < 100 and 100-300; \# significant between < 100 and > 300; \$ significant between 100 and 300 and $>300$; § significant between $<2 \%$ and $\geq 2 \%$. Table S4 displays the subgroup analysis of inflammatory markers according to the blood eosinophils in cases of patients without any signs of pneumonia $(n=322)$. Continuous parameters are displayed as Median and (IQR). * significant between < 100 and 100-300; \# significant between $<100$ and > 300; \$ significant between 100 and 300 and > 300 ; $\S$ significant between $<2 \%$ and $\geq 2 \%$. Table $\mathbf{S 5}$ displays the distribution of different types of ICS prescribed according to the eosinophil and non-eosinophil thresholds in cases of patients with a differential cell blood count at the day of admission $(n=417)$. Statistical analysis was performed using Chi-square test. Types of ICS that were administered in less than five cases were excluded from this analysis (Ciclesonide and Fluticasone furoate).

\section{Abbreviations}

COPD: Chronic Obstructive Pulmonary Disease; CMI: Case Mix Index; CRP: Creactive protein; eos: eosinophils; FEV1: Forced expiratory volume in one second; GOLD: Global Initiative for Chronic Obstructive Lung Disease; ICS: Inhaled corticosteroids; IQR: Interquartile range; LOS: Length of hospital stay; PCT: Procalcitonin; RCT: Randomized controlled trial; VC: Vital capacity

\section{Acknowledgements}

Not applicable.

\section{Authors' contributions}

T.G drafted the concept of this study, played a leading role in the acquisition, analysis and interpretation of the data as well as the writing of this manuscript. J. T played a major role in the acquisition, analysis and interpretation of the work. S. M played a major role in the acquisition of the data. A. E analyzed parts of the data. M. M, P. A, B. S and C. V substantively revised this work. All authors have approved the submitted version and have agreed to be personally accountable for their own contributions. They ensured that all questions relating to the accuracy and integrity of this work have been investigated and resolved.

\section{Funding}

This work has been funded in part by the Bundesministerium für Bildung und Forschung (Federal Ministry of Education and Research, ERACoSysMed2 - SysMed-COPD - FKZ 031 L0140, 031L0140B) to C.V. and B.S., and the vonBehring-Röntgen-Stiftung (66-LV07) to B.S.

\section{Availability of data and materials}

The datasets generated and/or analyzed during the current study are not publicly available due to further planned analyses from the same dataset.

\section{Ethics approval and consent to participate}

As this was a purely retrospective analysis from clinical routine data, we obtained a waiver by the ethics committee because a formal review was seen as not necessary (EM_MR_greulich_130320).

\section{Consent for publication}

Not applicable.

\section{Competing interests}

T.G reports personal fees from AstraZeneca, personal fees from BerlinChemie, personal fees from Boehringer-Ingelheim, personal fees from Chiesi, personal fees from CSL-Behring, grants and personal fees from Grifols, personal fees from GSK, personal fees from Novartis, grants from German Centre for Lung Research (DZL), Marburg, Germany (Deutsches Zentrum für Lungenforschung), outside the submitted work.

P.A reports grants from German Federal Ministry of Education and Research (BMBF) Competence Network Asthma and COPD (ASCONET), grants from AstraZeneca $\mathrm{GmbH}$, grants and non-financial support from Bayer Schering Pharma AG, grants, personal fees and non-financial support from Boehringer Ingelheim Pharma GmbH \& Co. KG, grants and non-financial support from Chiesi GmbH, grants from GlaxoSmithKline, grants from Grifols Deutschland $\mathrm{GmbH}$, grants from MSD Sharp \& Dohme GmbH, grants and personal fees from Mundipharma $\mathrm{GmbH}$, grants, personal fees and non-financial support from Novartis Deutschland $\mathrm{GmbH}$, grants from Pfizer Pharma $\mathrm{GmbH}$, grants from Takeda Pharma Vertrieb GmbH \& Co. KG, outside the submitted work. C.V reports grants and personal fees from AstraZeneca, grants and personal fees from Boehringer Ingelheim, personal fees from CSL Behring, personal fees from Chiesi, grants and personal fees from GlaxoSmithKline, grants and personal fees from Grifols, personal fees from Menarini, personal fees from Mundipharma, grants and personal fees from Novartis, personal fees from Nuvaira, personal fees from OmniaMed, personal fees from MedUpdate, outside the submitted work

B.S, J. T, S. M, A. E and M. M declare that they have nothing to disclose.

\section{Author details}

'Department of Medicine, Pulmonary and Critical Care Medicine, University Medical Centre Giessen and Marburg, Philipps-University, Centre for Lung Research (DZL), 35043 Marburg, Germany. ${ }^{2}$ Department of Pneumology and Critical Care Medicine, Cologne-Merheim Hospital, ARDS and ECMO Centre, Kliniken der Stadt Köln gGmbH, Witten/Herdecke University Hospital, 51109 Cologne, Germany. ${ }^{3}$ Institute for Lung Research, Philipps-University, Centre for Lung Research (DZL), 35043 Marburg, Germany.

Received: 2 January 2020 Accepted: 16 April 2020

Published online: 06 May 2020

\section{References}

1. Hurst JR, Vestbo J, Anzueto A, Locantore N, Mullerova H, Tal-Singer R, et al Susceptibility to exacerbation in chronic obstructive pulmonary disease. N Engl J Med. 2010;363:1128-38.

2. Singh D, Agusti A, Anzueto A, Barnes PJ, Bourbeau J, Celli BR, et al. Global strategy for the diagnosis, management, and prevention of chronic obstructive lung disease: the GOLD science committee report 2019. Eur Respir J. 2019:53:1.

3. Vedel-Krogh S, Nielsen SF, Lange P, Vestbo J, Nordestgaard BG. Blood eosinophils and exacerbations in COPD: the Copenhagen general population study. Am J Respir Crit Care Med. 2015;193(9):965. 
4. Siddiqui SH, Guasconi A, Vestbo J, Jones P, Agusti A, Paggiaro P, et al. Blood eosinophils: a biomarker of response to Extrafine beclomethasone/ formoterol in chronic obstructive pulmonary disease. Am J Respir Crit Care Med. 2015;192:523-5.

5. Pavord ID, Lettis S, Locantore N, Pascoe S, Jones PW, Wedzicha JA, et al. Blood eosinophils and inhaled corticosteroid/long-acting beta-2 agonist efficacy in COPD. Thorax. 2016;71:118-25.

6. Watz H, Tetzlaff K, Wouters EF, Kirsten A, Magnussen H, Rodriguez-Roisin R, et al. Blood eosinophil count and exacerbations in severe chronic obstructive pulmonary disease after withdrawal of inhaled corticosteroids: a post-hoc analysis of the WISDOM trial. Lancet Respir Med. 2016:4:390-8.

7. Papi A, Vestbo J, Fabbri L, Corradi M, Prunier H, Cohuet G, et al. Extrafine inhaled triple therapy versus dual bronchodilator therapy in chronic obstructive pulmonary disease (TRIBUTE): a double-blind, parallel group, randomised controlled trial. Lancet. 2018;391(10125):1076. https://doi.org/10. 1016/S0140-6736(18)30206-X.

8. Lipson DA, Barnhart F, Brealey N, Brooks J, Criner GJ, Day NC, et al. Oncedaily single-inhaler triple versus dual therapy in patients with COPD. N Engl J Med. 2018;378:1671-80.

9. Ferguson GT, Rabe KF, Martinez FJ, Fabbri LM, Wang C, Ichinose M, et al. Triple therapy with budesonide/glycopyrrolate/formoterol fumarate with cosuspension delivery technology versus dual therapies in chronic obstructive pulmonary disease (KRONOS): a double-blind, parallel-group, multicentre, phase 3 randomised controlled trial. Lancet Respir Med. 2018;6:747-58.

10. Bafadhel M, Greening NJ, Harvey-Dunstan TC, Williams JE, Morgan MD, Brightling CE, Hussain SF, Pavord ID, Singh SJ, Steiner MC. Blood eosinophils and outcomes in severe hospitalised exacerbations of COPD. Chest. 2016; 150(2):320.

11. Bafadhel M, Peterson S, De Blas MA, Calverley PM, Rennard SI, Richter K, et al. Predictors of exacerbation risk and response to budesonide in patients with chronic obstructive pulmonary disease: a post-hoc analysis of three randomised trials. Lancet Respir Med. 2018;6(2):117.

12. Pascoe S, Barnes N, Brusselle G, Compton C, Criner GJ, Dransfield MT, et al. Blood eosinophils and treatment response with triple and dual combination therapy in chronic obstructive pulmonary disease: analysis of the IMPACT trial. Lancet Respir Med. 2019;7:745-56.

13. Duman D, Aksoy E, Agca MC, Kocak ND, Ozmen I, Akturk UA, et al. The utility of inflammatory markers to predict readmissions and mortality in COPD cases with or without eosinophilia. Int J Chron Obstruct Pulmon Dis. 2015;10:2469-78.

14. MacDonald MI, Osadnik CR, Bulfin L, Hamza K, Leong P, Wong A, et al. Low and high blood eosinophil counts as biomarkers in hospitalized acute exacerbations of COPD. Chest. 2019;156:92-100.

15. Bafadhel M, McKenna S, Terry S, Mistry V, Reid C, Haldar P, et al. Acute exacerbations of chronic obstructive pulmonary disease: identification of biologic clusters and their biomarkers. Am J Respir Crit Care Med. 2011;184: 662-71

16. Pascoe S, Locantore N, Dransfield MT, Barnes NC, Pavord ID. Blood eosinophil counts, exacerbations, and response to the addition of inhaled fluticasone furoate to vilanterol in patients with chronic obstructive pulmonary disease: a secondary analysis of data from two parallel randomised controlled trials. Lancet Respir Med. 2015;3:435-42.

17. Greulich T, Vogelmeier CF. Blood eosinophils as a marker of eosinophilic exacerbations in COPD. Lancet Respir Med. 2018;6:e17.

18. Simon L, Gauvin F, Amre DK, Saint-Louis P, Lacroix J. Serum procalcitonin and $C$-reactive protein levels as markers of bacterial infection: a systematic review and meta-analysis. Clin Infect Dis. 2004;39:206-17.

19. Huang DT, Yealy DM, Filbin MR, Brown AM, Chang CH, Doi Y, et al. Procalcitonin-guided use of antibiotics for lower respiratory tract infection. N Engl J Med. 2018;379:236-49.

20. Agusti A, Edwards LD, Celli B, Macnee W, Calverley PM, Mullerova H, et al. Characteristics, stability and outcomes of the 2011 GOLD COPD groups in the ECLIPSE cohort. Eur Respir J. 2013;42:636-46.

21. Soler-Cataluna JJ, Martinez-Garcia MA, Roman Sanchez P, Salcedo E, Navarro M, Ochando R. Severe acute exacerbations and mortality in patients with chronic obstructive pulmonary disease. Thorax. 2005;60:925-31.

22. Celli BR, Cote CG, Lareau SC, Meek PM. Predictors of survival in COPD: more than just the FEV1. Respir Med. 2008;102(Suppl 1):S27-35.

23. Divo M, Cote C, de Torres JP, Casanova C, Marin JM, Pinto-Plata V, et al. Comorbidities and risk of mortality in patients with chronic obstructive pulmonary disease. Am J Respir Crit Care Med. 2012;186:155-61.
24. Crisafulli E, Torres A, Huerta A, Guerrero M, Gabarrus A, Gimeno A, et al. Predicting in-hospital treatment failure $(</=7$ days $)$ in patients with COPD exacerbation using antibiotics and systemic steroids. Copd. 2016;13:82-92.

25. Crisafulli E, lelpo A, Barbeta E, Ceccato A, Huerta A, Gabarrus A, et al. Clinical variables predicting the risk of a hospital stay for longer than 7 days in patients with severe acute exacerbations of chronic obstructive pulmonary disease: a prospective study. Respir Res. 2018;19:261.

26. Tang B, Huang D, Wang J, Luo LL, Li QG. Relationship of blood eosinophils with fractional exhaled nitric oxide and pulmonary function parameters in chronic obstructive pulmonary disease (COPD) exacerbation. Med Sci Monit. 2020;26:e921182.

27. Ko FWS, Chan KP, Ngai J, Ng SS, Yip WH, Ip A, et al. Blood eosinophil count as a predictor of hospital length of stay in COPD exacerbations. Respirology. 2020;25:259-66.

\section{Publisher's Note}

Springer Nature remains neutral with regard to jurisdictional claims in published maps and institutional affiliations.
Ready to submit your research? Choose BMC and benefit from:

- fast, convenient online submission

- thorough peer review by experienced researchers in your field

- rapid publication on acceptance

- support for research data, including large and complex data types

- gold Open Access which fosters wider collaboration and increased citations

- maximum visibility for your research: over $100 \mathrm{M}$ website views per year

At $\mathrm{BMC}$, research is always in progress.

Learn more biomedcentral.com/submissions 